\title{
ACROMEGALY AND GIGANTISM Including A NEW SYNDROME IN CHILDHOOD
}

\author{
By S. Leonard Simpson, M.A., M.D.(Cantab.), F.R.C.P.(Lond.) \\ Physician (with charge of Endocrine E Diabetic Clinics), Willesden General Hospital ; Endocrinologist, Princess Louise \\ Children's Hospital ; Consultant Endocrinologist, St. Mary's Hospital
}

The characteristic endocrine giant is a patient with an eosinophil adenoma of the anterior pituitary gland, the hypersecretion of growth hormone having been operative before union of the ephiphyses of the long bones and subsequently producing the added complication of acromegaly if the hypersecretion continues in late adolescence or adult life. In relatively minor degree both gigantism and acromegaly occur more frequently without an actual eosinophil adenoma and tend to have a high incidence in some families and indeed in some races, e.g. the Swedes. These are obviously genetically determined variations of normality.

Clinical accounts of gigantism go back to 1567 (quoted by Sternberg, 1897), but fables and folklore carry them back to much earlier times and we may include the biblical tale of Goliath and David. Pierre Marie used the name 'acromegalie ' in 1866 , Minkowski connected the disease with the pituitary gland in 1887 , and Benda associated it with the eosinophil cells in 1900. Cushing and Davidoff (1927) firmly established the relation with eosinophil cell adenoma, or hyperplasia; and Cushing in 1912 recorded an interesting case of acromegaly in a man of 33 , with a primary cerebellar cystic tumour, a secondary hydrocephalus, and hyperplasia of the eosinophil cells of the anterior pituitary gland.

It is not the author's intention to spend time on the conventional descriptions of these disorders which are to be found in any good textbook, but rather to draw attention to less obvious features and problems.

Acromegaly does not usually manifest itself until adolescence or adult life, the excess of growth hormone having its initial point of action on the epiphyseal cartilage of the long bones. However, Atkinson (193I) recorded one case at the age of eight years and noted in the literature 25 cases in childhood. F. Mainzer and E. Yalausis (1937) describe a case of giantism and acromegaly in a boy of 14 following a severe fall, concussion and unconsciousness for three days. This was followed by progressive weakness and very rapid growth, although there was no measurement until his eighteenth birthday, $180 \mathrm{~cm}$. (6 ft.), and at 22 years, $224 \mathrm{~cm}$. ( $7 \mathrm{ft} .6$ in.). Extreme prognathism and coarsening of the features were indicative of acromegaly, but the bones remained slender. The genitals were entirely infantile, and no secondary sexual characteristics were present. The sella turcica was deformed and three times the normal size.

Acromegaly, not unexpectedly, tends to occur in tall people and Davidoff (1926) found in one series that the average height of men before the disease commenced was $6 \mathrm{ft} .2$ in., and in women $5 \mathrm{ft} .6$ in.

\section{Acromegaly and the Thyroid}

The thyroid gland may be appreciably enlarged in acromegaly and the basal metabolism moderately raised. If there is any truth in the pituitary thyrotrophic cause of thyrotoxicosis, it might well be substantiated by typical findings in acromegaly, but clinical thyrotoxicosis is a rarity, especially the picture of Graves' disease. Cushing and Davidoff (1927) found an increased basal metabolism (average 18 per cent.) in 49 of 72 cases of acromegaly. Davis (1940) in a series of 135 cases (of a total of 166 cases) found an average increase of 18 per cent. in 116 cases, and an average decrease of minus 7 per cent. in 17 cases, the remaining 2 being normal. He found enlargement of the thyroid gland in 86 of the 166 cases and obvious adenomata in 53 of these 86 cases, the adenomata varying from small nodules to large tumours that caused tracheal compression. As to correlation, the group of cases in which the thyroid gland contained definite adenomata comprised the cases in which there was the greatest increase of metabolism (mean B.M.R. plus 24 per cent.); in the group of cases in which the thyroid gland was palpable, the B.M.R. average was plus I I per cent.; and the group in which the thyroid was not palpable clinically had an average B.M.R. of plus 9 per cent. Resection of the thyroid gland was carried out in 27 cases for 'one or more of the following reasons:-respiratory obstruction, present in 7 cases; evidence of hyperthyroidism, present in 24 cases, and hypertensive heart disease 
in association with hyperthyroidism which was present in 5 cases.' There were five deaths in the series, and Davis regards these cases as poor surgical risks. The B.M.R. after thyroidectomy was recorded in only 12 cases and of these it decreased in 10 and was unchanged in 2 . The decrease varied from 2 to 53 with an average of 13 per cent.

Fortunately, only five patients received preoperative iodine so that the pathological anatomy of the thyroid gland was undistorted. In no less than 23 cases the histological picture was described as 'adenoma in colloid thyroid'; in $\mathbf{I}$ as colloid thyroid gland, and in 3 only as diffuse parenchymatous hypertrophy. Cushing and Davidoff (1927) found that surgical removal of a pituitary eosinophil adenoma in patients with acromegaly, goitre and raised B.M.R. resulted in a fall of B.M.R. as striking as the effect of thyroidectomy. It would therefore appear probable that the thyrotropic hormone is secreted in excess in acromegaly, and we then must ask ourselves the question why does it in the majority of cases produce a colloid adenomatous goitre and not the diffuse parenchymatous hyperplasia of Graves' disease? We cannot reject the thyrotropic stimulus mechanism theory of Graves' disease since injection of thyrotropic hormone in some species of animals does produce this hyperpl tsia picture. We must, therefore, conclude that the character of the response of the thyroid gland is at least as important a factor as the stimulus.

The above facts gleaned from acromegaly, as well as others learned from certain types of Cushing's disease, cannot be ignored in any attempts to theorize about the problems of toxic goitre.

\section{Acromegaly and Diabetes Mellitus}

The occurrence of diabetes mellitus as a complication of acromegaly has long been known, and the work of Young (1937) on the pituitary diabetogenic hormone gives a theoretical basis for the clinical facts. Cushing and Davidoff (1927) found 12 cases of diabetes mellitus in a group of roo acromegalics. It is often stated that the diabetes of acromegaly is relatively mild and innocuous, but in a series of autopsies Cushing and Davidoff (1927) found that of 44 acromegalics no less than I I died in diabetic coma. The initial diabetes may well be entirely pituitary in origin, but later there is probably degeneration of the islets as in Young's dogs, and a superimposed pancreatic diabetes. At this later stage treatment of the acromegaly would have no influence on the severity of the diabetes. In the earlier stages, not only may successful treatment of the acromegaly abolish or improve the diabetes, but the diabetes also varies in intensity with the spontaneous variations in the course of the primary acromegaly. The diabetes of acromegaly may be very resistant to insulin and several hundred units may be required daily. The renal threshold may be high and frequent blood sugars essential for an accurate assay of the severity of the disorder. Fasting blood sugars may be normal or near normal and yet be followed by a severe diabetic type of carbohydrate tolerance curve. Polyuria, polyphagia and polydipsia may be symptoms of acromegaly even in the absence of diabetes. Coggeshall and Root (1940) describe 16 cases of diabetes mellitus in acromegalics of which 3 died in diabetic coma. The average interval between the onset of acromegaly and diabetes was nine years, but varied between one and 22 years. Three of their cases were secondary to giantism without acromegaly. They quote White's findings to the effect that a considerable proportion of diabetic children are above the average height at the onset of their diabetes and also show earlier bony, dental and sexual development. This obviously raises the question of the primary pituitary origin of ordinary diabetes mellitus.

\section{Acromegaly and the Parathyroids}

Bauer and Aub (1940) reviewed the experimentalo and clinical evidence of correlation between the two. An alkaline extract of the anterior pituitary gland caused hypertrophy of the parathyroid glands in rabbits and rats. They noted a case reported by Scriver and Bryan of acromegaly with osteoporosis and a negative calcium balance, and studied four acromegalics in their own series. They found an increased urinary excretion of calcium and phosphorus but no change in faecal or serum values. They excluded hyperthyroidism as a factor, as in this disorder the faecal as well as the urinary excretion of calcium and phosphorus is increased. They found that the excretion of calcium varied with the phase of activity of the acromegaly and could be reduced by deep radiation of the pituitary gland, but did not regard proof of secondary hyperfunction of the parathyroids as absolute.

\section{Acromegaly and the Gonads}

In adults there may be an initial increase in libido and potency, but soon impotence follows, or it may be one of the earliest symptoms. These two phases may also be found in adolescence, and in spite of normal or large genitals there may be incomplete secondary sexual characteristics. Further, with apparently normal sexual development, there may be delayed union of the epiphyses so that a rapid spurt in growth may occur at the age of 20 or more. In the female, amenorrhoea is common, but anovular menstruation and menorrhagia occur 
as well as normal menstruation. The thymus gland is often enlarged.

\section{Racial Acromegaly and Gigantism}

Allowing for individual variations and for the absence of clear-cut ethnological divisions, there is no doubt that some races are tall, others are short. Evidence for an underlying pituitary mechanism is forthcoming in the greater incidence of mild acromegalic features in some of the taller, bigboned European races. and was found to contain an excess of posterior pituitary antidiuretic hormone. Further, this excess disappeared with successful radiotherapy to the pituitary gland and at the same time the water balance returned to normal (Ellinger, Hare and Simpson, 1937). It was therefore postulated that hyperactivity of the posterior pituitary gland was present and the name diabetes tenuifluus w.s given to the disorder (Simpson, 1948). The sweating was assumed to be secondary. It is difficult to know why the posterior pituitary

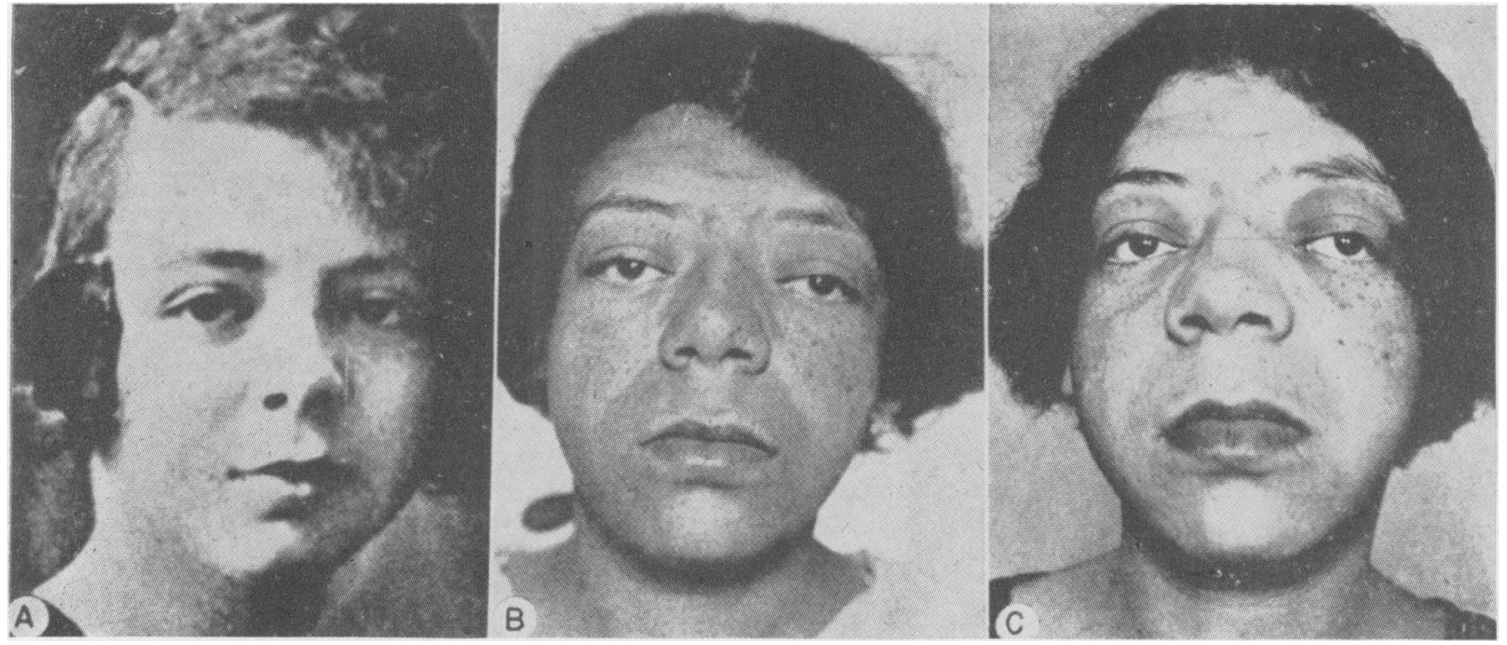

Fig. I.-Racial Acromegaly. A, aged 24 years, just prior to onset of acromegaly; B, aged 33 years, when first seen ; $\mathrm{C}$, aged $3^{8}$ years. Note startling negroid changes in features, especially the nose, lips and forehead, also the pigmentation and darker frizzier hair.

(Reproduced by kind permission of Drs. Goldberg and Lisser.)

The negro race is on the whole a tall race, and demonstrates what might be regarded as acromegaloid features in the facies, e.g. thick lips and broad nose. Without speculating on its more general significance, Goldberg and Lisser (1942) describe a case of acromegaly in a woman of 33 of American parents of French-Norwegian extraction. There was probably also an undetermined negroid admixture, not at all apparent in her early features. After the onset of acromegaly, her appearance became frankly negroid (Fig. I).

\section{Excessive Perspiration in Acromegaly}

Cushing and Davidoff (1927) reported excessive perspiration in no less than 60 per cent. of acromegalics and its degree appears to vary with the phase of activity of the primary disease. Its cause is uncertain, but it may be associated with the excessive development and hyperfunction of the sweat glands. In one such case the writer was impressed by the fact that there was an associated positive water balance, more fluid being taken than was excreted. This may have been caused by the perspiration but, to test an alterative hypothesis, the cerebrospinal fluid was examined gland should be hyperactive in acromegaly, a disease of the anterior pituitary; and more easy to comprehend why diabetes insipidus sometimes occurs as a complication, the pars nervosa being destroyed by an invading eosinophil adenoma. Nevertheless, such hyperfunction is possible as in the adrenal, where a neuroblastoma of the medulla may rarely stimulate the cortex to produce some degree of virilism, presumably due to secondary hyperfunction of the cortex.

There is, however, an alternative explanation of these findings, namely that excessive perspiration, in the same way as dehydration or absence of fluid intake, stimulates the posterior pituitary to physiological hyperfunction.

\section{The Course and Treatment of Acromegaly and its Biochemical Control}

The course of acromegaly is variable. Its active phase may give way to an involutionary or exhaustion phase. Certainly excessive muscular strength may be evident initially and may be followed by marked weakness. The author ventures to suggest that in Biblical times Goliath's victories were obtained in the active phase of his disease 
and that David was lucky enough to meet him after weakness had set in. In more modern times we have seen a European acromegalic boxer reach the heavyweight championship class and retire prematurely for physical reasons. The same phenomenon is found in some forms of giantism. The phase of excessive strength must, in the author's view, be attributed to androgen secretion by the adrenal cortex, comparable to that in the Herculean type of sexual precocity. If such abnormal strength persists during the phase of impotence we are dealing with a paradox in which perhaps simultaneous hypersecretion of adrenal oestrogens plays a part.

In general, the waxing and waning of acromegaly gives no cause for complacency, for progress of the disease is grievous and ultimately fatal. Surgical removal of a pituitary adenoma is a radical measure giving good results in the hands of experts, although haemorrhage may be troublesome and even fatal. Increasing optic atrophy may be considered an indication for surgery. Irradiation of the pituitary gland is a comparatively safe procedure and its effectiveness may well be explored initially (Hurxthal, et al., 1949). Ellis (I949) recently reviewed the literature, indicating a favourable response in some 50 per cent. of cases, and recorded his own encouraging results, preferring moderate doses of 1,200 to $1,800 \mathrm{r}$. to the heavier dosages up to $3,000 \mathrm{r}$. previously employed. He believes that if irradiation fails, radon seeds should be given a trial before surgery, but the danger of haemorrhage in the course of implanting radon seeds into a pituitary eosinophil adenoma is by no means negligible (Northfield, 1949). Claims have been made for the inhibition of the pituitary by large doses of oestradiol and testosterone, a somewhat tentative medical approach of symptomatic benefit. Schrire and Sharpey-Schafer (1938) point out that pituitary activity may be judged by the quantities of creatine and creatinine in the urine, and the effect of testosterone and oestradiol by the resulting diminution in these quantities. Schrire (1948) also uses creatine and creatinine to study the degree of activity of the hyperpituitarism at any phase. Thus he found that in active giantism and acromegaly, creatinine is excreted in large quantities, creatine often in excessive amounts, but both inconsistently. $\mathrm{He}$ and Sharpey-Schafer (1938) also drew attention to the fact that pituitary gonadotropic hormone increases creatinine excretion, whilst thyrotropic hormone promotes creatine excretion.

Kinsell, Michaels, Li and Larsen (1948) use the serum inorganic phosphorus as an index of pituitary hyperfunction and effectiveness of treatment after acknowledging the original discovery of Albright that serum inorganic phosphorus is raised in the active phase of the disease. They note that serum phosphorus is also raised during childhood growth and falls in post-puberty growth, which observations, coupled with the depression of serum phosphorus in acromegalics by testosterone and/or oestrogens, led them to the hypothesis that there is a pituitary type of growth associated with high serum phosphorus and a steroid type (or phase) of growth associated with normal serum phosphorus. Their normal range of serum phosphorus was 3 to $4 \mathrm{mgm}$. per cent., and values in their acromegalics were in the neighbourhood of $5 \mathrm{mg}$. per cent. or higher $(4 \mathrm{mg}$. per cent. might be considered the normal limit for most laboratories). They confirm Albright's observation that the serum phosphatase is not raised in acromegaly, with the exception of one male acromegalic giant aged 20 , with open epiphyses, who had a persistent elevation of the phosphatase. This group of investigators, working in Professor Herbert Evans' laboratories in California, were also able to demonstrate an excess of growth hormone in the serum of their acromegalics, and its parallel fluctuation with the serum phosphorus during treatment. Contrary to many reports, they also found that with an adequate diet, their acromegalics were on positive calcium, phosphorus and nitrogen balance. The suggested dosage for hore mone therapy of acromegalics is given as 25 tof $50 \mathrm{mg}$. of testosterone injected daily for the male and $0.3 \mathrm{mg}$. of ethinyl oestradiol daily by mouth for the female. Improvement is claimed.

\section{Gigantism}

Moderate gigantism is not uncommon and is usually associated with considerable muscular strength. This is probably due to the large quantity of androgens secreted by the overactive adrenals, with or without multiple adenoma formation, the adrenal activity being secondary to pituitary hyperfunction. The muscular strength of a gigantic acromegalic boxer has already been mentioned. Gigantism is, however, not necessarily complicated by acromegaly and the associated strength may endure throughout life. Recently we have seen a team of overseas golfers whose exceptional skill was paralleled by their exceptional height, strength and muscular development. Their hands were big and enfolded the golf club in an embracing powerful grip. One physically miniature British golfer defeated their most massive representative by greater skill and timing, but that does not negative the above general impressions or the obvious advantages, other things being equal, of hyperfunctioning pituitary and adrenal glands within physiological limits.

As to historical giants, Gibbon in the second edition (1776) of his classical work gives the 
following description of a young Thracian peasant who was later to become the Emperor and inhuman tyrant Maximin. Having floored in succession 16 of the stoutest camp followers at the military games he, on the following day, attracted the notice of the Emperor Alexander Severus by easily keeping pace with him on horseback over a long distance. Asked by the Emperor whether he would wrestle after his race, he was at once matched against seven of the strongest soldiers in the Army simultaneously, and gained the verdict with ease. His stature, according to Gibbon, exceeded $8 \mathrm{ft}$. He could draw a loaded wagon, break a horse's leg with his fist, crumble stones in his hand and tear up trees by the roots. His appetite was in keeping with his strength, for he would drink an amphora (about 7 gal.) of wine and eat 30 to $40 \mathrm{lb}$. of meat daily. Wrestling, incidently, continues to be a sport which attracts relative giants with or without acromegalic features.

It might well be argued that tall people are not always strong and some are definitely weaker than the average. This may be clinical evidence for the existence of a pituitary growth hormone unassociated with a pituitary adrenotrophic hormone. Since some such cases later develop acromegalic features, the author is inclined to recognize such a group. In others, however, who have a late puberty and grow to excessive height because their epiphyses remain ununited unduly long even into the third decade and whose genitals do not respond to gonadotrophic hormone, there appears to be a primary hypogonadism. In such cases, the small genitals in adolescence justify the name eunuchoids, but mild cases are too numerous to be regarded as pathological, and their ultimate spontaneous sexual development may be quite normal. Adolescent acromegalics, in whom there is also delayed puberty and delayed union of the epiphyses permitting an excess of growth hormone to act on the long bones over an excessive period of time, form an intermediate group.

Where gigantism is due to a pituitary eosinophil adenoma, optic atrophy is not uncommon. In one girl of 14 seen in out-patients because of unduly rapid growth ( $5 \mathrm{ft}$. I I in.) and some enlargement of the hands, papilloedema was a surprising finding. A ventriculogram revealed dilatation of the third ventricle; and the autopsy, after a cerebral operation, showed stenosis of the aqueduct of Sylvius by an astrocytoma. This patient had red abdominal lineae distensae and some facial plethora, but a normal red cell count. The pituitary gland was apparently normal on histological examination, although one must assume excessive secretion of growth hormone.

Gigantism, or giantism, is often associated with mild acromegaly within what might be termed almost physiological limits, resulting in virile attractive personalities. Many a 'he-man' of the films owes his box office attraction to his pituitary gigantic skeletal development, his resolute prognathic lower jaw and his deep vibrant voice, emanating from an overdeveloped acromegalic larynx.

\section{Acromegaly in Childhood and Adolescence}

Atkinson (193I) collected no less than 32 cases from the literature of which he accepts $25-15$ males and ro females. The disease usually commenced at about the age of puberty, e.g. 12 years, but there was one case at six years, that described by Walker: a male, aged six years, with both acromegaly and gigantism; rapid growth after measles, especially of the hands and feet; no enlargement of the lower jaw; progressive loss of sight of right eye from age of eight (suggesting eosinophil adenoma and optic atrophy). Another patient was aged seven, also with acromegaly complicating gigantism; and another aged eight.

1 would like to describe briefly here the insidious onset of acromegaly in a male patient about the time of chronological puberty, with some interesting features and paradoxes. The patient (Fig. 2) was first seen by me having just reached the age of $I 7$. His father was $5 \mathrm{ft}$. I I in., the mother was tall, and all her male folk over $6 \mathrm{ft}$. The patient weighed $\mathrm{I} 4 \mathrm{lb}$. at birth. $\mathrm{He}$ was always a tall boy and at 16 his height was 73 in. and his weight $152 \mathrm{lb}$. His breasts enlarged at the age of 15 and his voice broke at 16 , but in a few months returned to his boyish high pitch. He experienced some erections but no emissions. He was always very tired and wanted to be with his parents all the time. His hands and feet were very large (boots size 12), and his features thickened. His genitals were of adult size. He had plentiful pubic hair but limited horizontally as in the female. Axillary hair was present with hair on the legs, but none on the face. The 17 -ketosteroids were normal (I3.6 mg. per day). Nevertheless the implantation of $800 \mathrm{mg}$. testosterone minimized the gynaecomastia, increased the frequency of erections and increased the muscular strength. The photograph was taken before treatment. X-rays showed the pituitary fossa to be slightly enlarged and the epiphyses of the long bones to be united. One would hazard that the adrenals were hyperplastic and were secreting oestrogens as well as androgens. Clinically this was a case of gigantism and acromegaly with delayed incomplete puberty and gynaecomastia.

From the wealth of clinical material in Cushing's 1912 monographs on the pituitary body, two cases are chosen to illustrate interesting aspects. Case $2 \mathrm{I}$ illustrates the genetic factor in gigantism and 
acromegaly and evidence at childbirth of things to come. The patient, a male, came under Cushing's care at the age of 48 with gross acromegaly. His maternal grandfather was a giant, famous in his native land of Hungary, but his parents were average. At birth he was said to be as large as a child of one year of age and extraordinarily fat, the fatness preventing him walking until the age of three. At the age of 12 he was $6 \mathrm{ft}$. in height and of Herculean strength. At the age of ${ }_{15}$ severe headaches commenced. There is no note about puberty, but sexual function appears to have been at least normal. At the age of 27 he married a

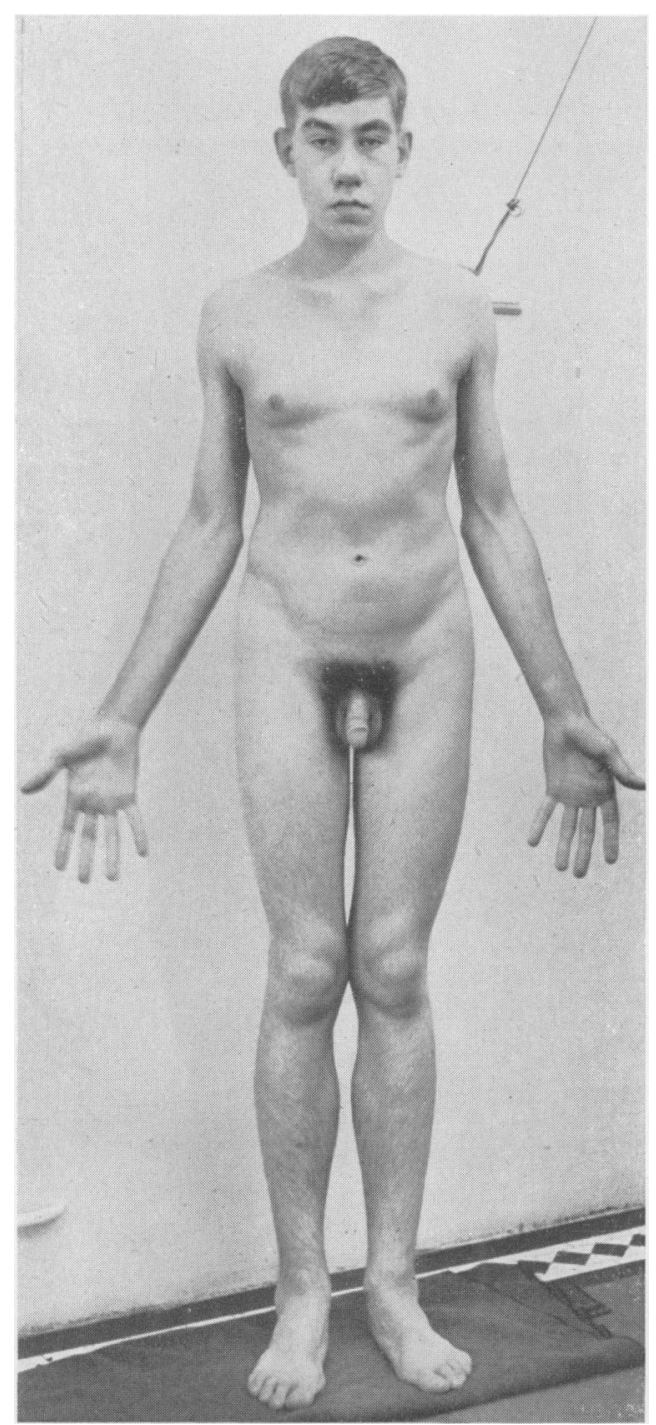

Fig. 2.-Acromegaly in a boy of 17 , with incomplete puberty and gynaecomastia. very big womar, (which complicates the story), but the first child was too large to be born, the second weighed $I_{7} \mathrm{lb}$. at birth, the third was said to be enormous and died soon after. The onset of acromegaly was apparently insidious in adult life.

Case 32 was seen by Cushing at the age of $3^{6}$ measuring $8 \mathrm{ft} .3$ in. and with acromegalic features. The patient, a male, began to grow rapidly at $\mathrm{I}_{5}$, but never developed facial, axillary or body hair except a few pubic hairs. The genitalia were infantile and the testicles atrophic with no interstitial cells and few atrophic tubules. The adrenals were diminutive and difficult to locate. (In two other patients, one with persistent excessive hairiness in a male, signs of Addison's disease including pigmentation were present in the hypopituitary phase of the disease.) One of the writer's male acromegalics was $7 \mathrm{ft}$. 6 in. at the age of 21 and $8 \mathrm{ft} .3$ in. at the present age of 25 .

Case 30, a male, illustrates that in spite of apparent normal sexual development the epiphyses may remain open since the patient grew from $6 \mathrm{ft}$. to $6 \mathrm{ft} .2$ in in his twenty-ninth year, when acromegaly supervened.

Case I, a male, showed very rapid growth from the age of $\mathrm{r}_{3}(6 \mathrm{ft} .4$ in.). At 19 he developed uncontrolled libido sexualis, whilst at 27 he was acromegalic and had lost all libido.

Cushing incidentally describes a girl of $2 \frac{1}{2}$ whके began to grow rapidly in height and to put on fat; also developing sleepiness, polydipsia and polyphagia. Autopsy of the skull showed ' an unusual cell sarcoma,' flattening the pituitary fossa.

\section{Hirsutism}

The author has seen at least five cases in which hirsutism followed acromegaly, and a sixth in which hirsutism was associated with mild gigantism and acromegaly. The mechanism is a secondary hyperplasia with multiple adenoma in the adrenal cortex and hypersecretion of androgens. The first was a woman of 32 who developed acromegaly at the age of 23 and hirsutism at the age of 27, particularly of the face but also on thighs and abdomen (Simpson, I948) (Fig. 4). She also had a symptomless goitre. The second (Fig. 5) was a woman of 60 under treatment for hypertension (200/130) and cardiac failure, complicating her acromegaly. This started in early life, a sister stating that the patient always had an enormous appetite and large hands and feet. The hairiness was present from the age of 30 or before. Her I 7-ketosteroids were 2 to $3 \mathrm{mg}$. per day on one occasion, and 4 to $5 \mathrm{mg}$. per day two weeks later; the thyroid was grossly enlarged. The third patient was a woman of 33 years suffering from delusional insanity. She was admitted to a mental 


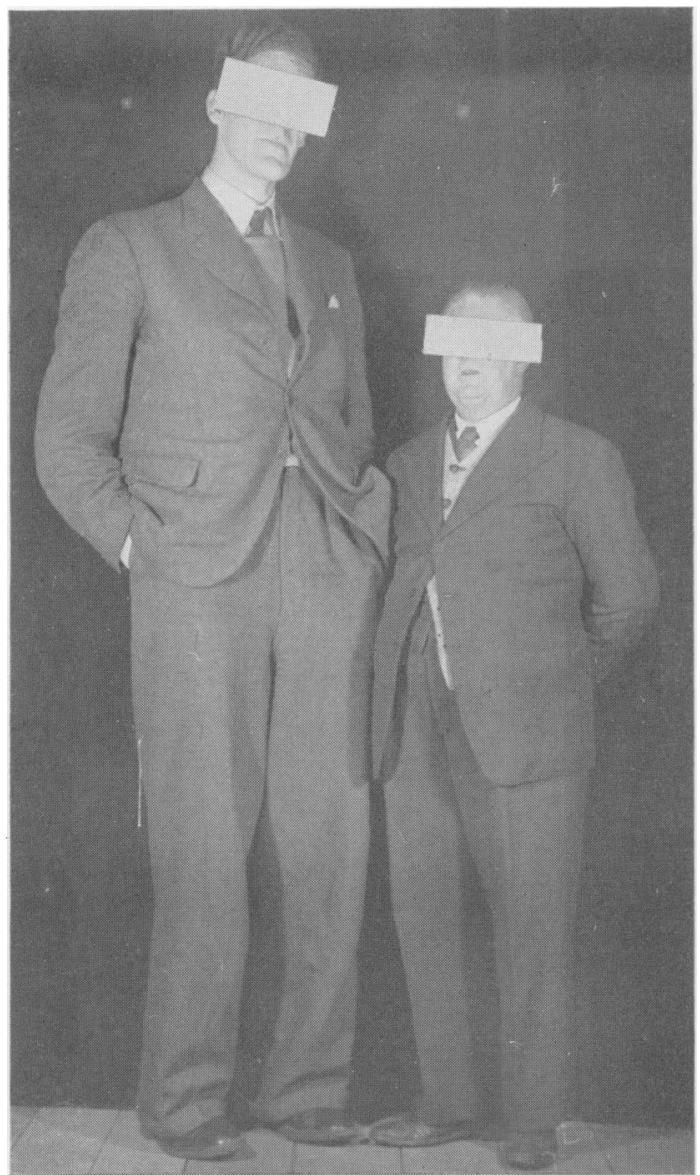

Fig. 3.-Gigantism with mild acromegaly in a male aged 25 (author's case). Enlarged pituitary fossa and bilateral optic atrophy. Height, $7 \mathrm{ft} .6$ in. Boots, size I7.

hospital with acute mania, hallucinations and delusions. There was a scar of a previous thyroidectomy. The I7-ketosteroids were unexpectedly low, I. 5 and $3.1 \mathrm{mg}$. per day, and the plasma phosphorous $3 \mathrm{mg}$. She made a spontaneous recovery from her mental state, but has not been seen since. The sixth (Fig. 6) was a very unusual case, a woman of $2 \mathrm{I}$, with big bones and on the tall side for a woman, $6_{5}$ in., with some prognathism, who developed amenorrhoea and hirsutism at the age of I6. The I 7-ketosteroids were very high (I $40 \mathrm{mg}$.) and a large right adrenal adenocarcinoma was removed. Menstruation returned but hirsutism persisted. Ten years later the ketosteroids remained high (70 mg.) but laparotomy failed to reveal an ovarian or adrenal neoplasm.

Augmented Growth in Childhood, a New Syndrome (Adipose Gynandrism and Gynism)

In 1948 the author attempted to separate a syn- drome in males from the ill-defined collection of fat boys and from Fröhlich's or pseudo-Fröhlich's syndrome. Its characteristics were:-puberty was delayed some years, the patient was fat, often from birth, the pubic hair was late in appearing and was limited horizontally as in the female, the facial skin was smooth and of fine texture as in the female, facial hair appeared late and remained scanty, the trunk was relatively free from hair, the hips were broad in relation to the shoulders, the gait was somewhat waddling, the stance and temperament were feminine and the patients were not good at games. The author gave the syndrome the name of adipose gynandrism and suggested that it was of pituitary or hypothalmic pituitary origin, that it differed from Fröhlich's syndrome in that sexual maturity developed spontaneously although belatedly, and that the patients were fertile and could reproduce themselves. (Gonadotrophins were effective if used to accelerate genital development.) Lineae distensae were present and frequently purple. Their height varied and they might be tall. In the photograph illustrating the syndrome (Fig. 7) the boy of eight has a height of 52 in. compared with an average of 48 in. In the classical Frohlich's syndrome the patients are subnormal in height.

This and allied syndromes both in males an£̧ females have been studied further. Thus a boy of IO $\frac{1}{2}$ years with infantile penis and one descended5 testicle of infantile dimension, measured $58 \frac{1}{2}$ in: (average 53 in.) and weighed I4I lb. (average 70 lb.). He was $7 \frac{1}{2} \mathrm{lb}$. at birth but soon put on weight. $\mathrm{He}$ was always taller than children of his own age. His father was $6 \mathrm{ft}$. and thin, his mother average. He was emotional and had temperamental outbursts, suggesting perhaps a hypothalmic lesion. He had a feminine appearance, big pelvis, waddling gait and apparent development of breasts. He had no lineae distensae when first seen but six months later developed purple lineae distensae on the lower abdomen and thighs. Unfortunately he was treated with gonadotrophins and descent of the testes with acceleration of sexual maturity resulted.

Another lad of 17 , complaining of adiposity and I 5 st. $4 \mathrm{lb}$. in weight, was always some inches taller than his average contemporaries, but now only $5 \mathrm{ft} .8 \frac{1}{2}$ in., showed all epiphyses of the long bones completely united. $\mathrm{He}$ was said to have been a very big baby. His voice broke at $\mathrm{I}_{4}$ and pubic and axillary hair developed, although none was present on the face even at 17 . His penis was of normal size and the testicles small, but a large hydrocele was present on the left side. The remarkable feature, about which the patient was much distressed, was numerous dark red striae on abdomen, thighs, shoulders, breasts, and back, 

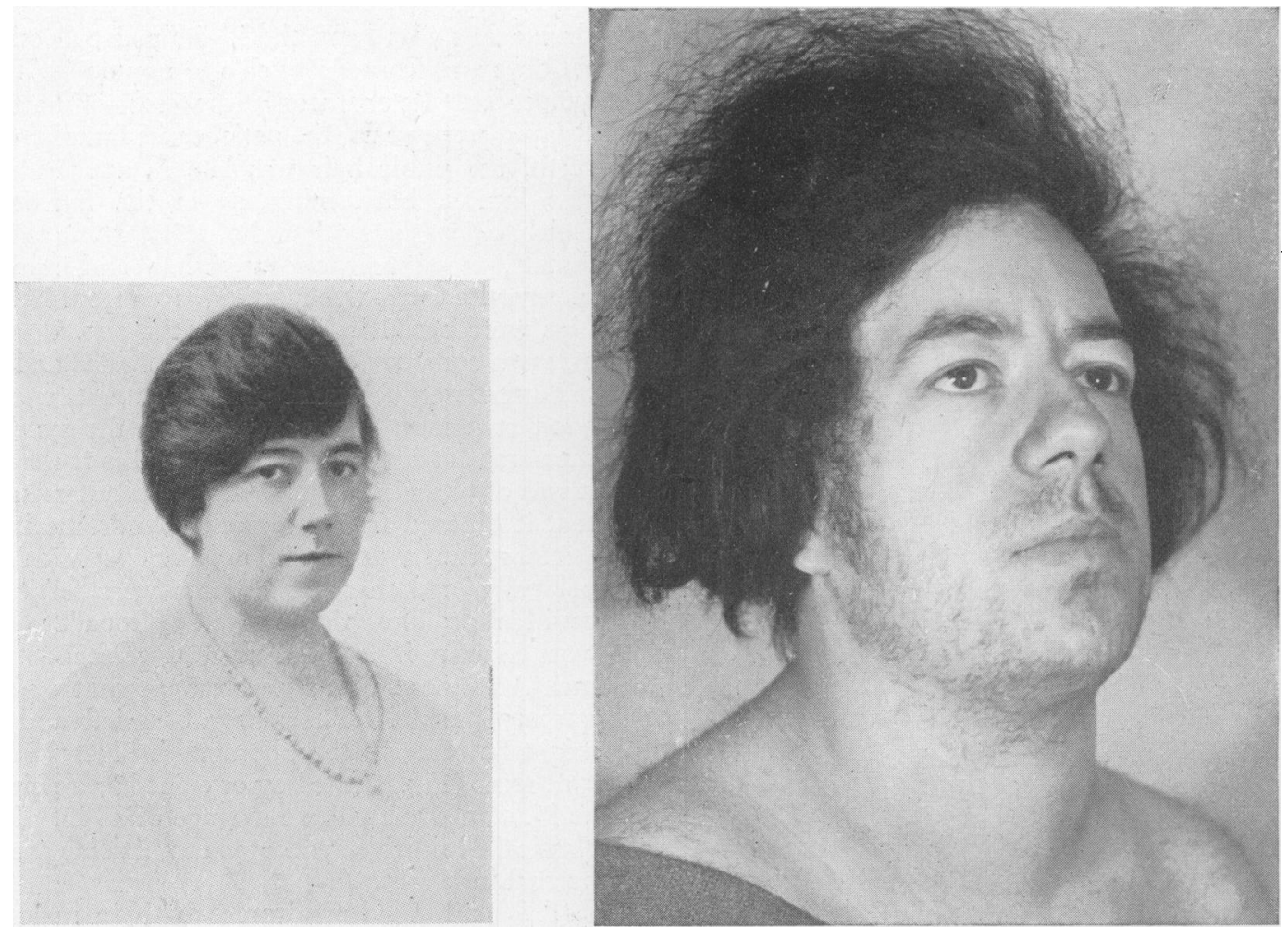

Fig. 4.- Acromegaly with secondary virilism and goitre. (a) The patient aged 20, and (b) aged 32.

which appeared at the age of 15 , although a few red horizontal striae across the back were present from the age of seven. The number and wide distribution of these striae was much greater than could be explained by the degree of adiposity, and another more direct factor in their production appears probable.

Another male patient weighed $8 \frac{1}{2} \mathrm{lb}$. at birth but soon became overweight (Fig. 8). From the age of 3 to the age of 1o he approximated to normal weight, 'but then again began to put on weight and at 13 weighed 20 st. Seen at the age of I6 he weighed 32 st. and was $5 \mathrm{ft}$. $9 \frac{1}{2}$ in. in height. He was said to be always taller by some inches than his average contemporaries. The body was generally hairless, but a few soft hairs were present on the pubis, axillae and chin. The genitals were of average size. His voice was high pitched, his pelvis broad. His blood pressure was 200/120. Deep red lineae distensae were present over the buttocks, abdomen and breasts. The epiphyses of the long bones were nearly united and the bone age given radiologically as 18 . The carbohydrate tolerance test showed a flat curve 4I, 92, 83, 63, $96 \mathrm{mg}$. Blood cholesterol was I95 mg.; I7ketosteroids $9.8 \mathrm{mg}$. per 24 hours; II-oxysteroids, crude, $2.8 \mathrm{mg}$., fractionated, r.o mg., i.e. slightly above normal.
In females there appears to be a parallel syndrome to which the author's attention was drawn by the presence of red or purple lineae distensae. A point of interest is that these red lineae distensae may become white in the course of the period of observation before, during or after puberty. Some examples have been:-

A.L., first seen at the age of eight, height $4 \mathrm{ft}$. $2 \frac{1}{4}$ in. (average $4 \mathrm{ft}$.), weight $104 \mathrm{lb}$. (average $53 \mathrm{lb}$.), red lineae distensae on abdomen and buttocks, bluish mottling of legs, B.P. 126,90. One year later the lineae were white and had largely disappeared. She had lost $12 \mathrm{lb}$. in weight.

E.H. (Fig. 9), after measles at seven, gained rapidly in height and weight. Monthly nose bleeding from 9 to $\mathrm{I}_{3}$, when menstruation started. Seen at the age of 12 , height $5 \mathrm{ft} .3$ in. (average $4 \mathrm{ft}$. 9 in.), weight 2 ro lb. (average $82 \mathrm{lb}$.), some lower pubic and axillary hair present; breasts large; B.P. I I0/70. During the second half of her thirteenth year her height remained at $5 \mathrm{ft}$. 5 in. and her epiphyses were united, although they were ununited six months previously. At $12 \frac{1}{2}$ purple lineae distensae appeared on the abdomen. At 13 these became white, while at the same time red ones appeared on the breasts.

B.McC., obese since an attack of scarlet fever at the age of eight. Seen at the age of 10 years i I 


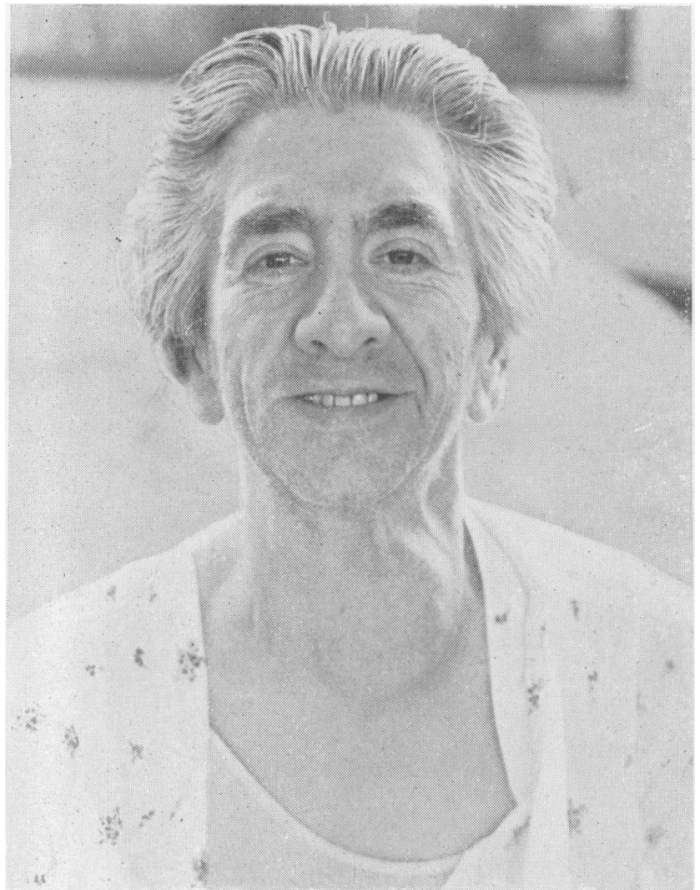

Fig. 5.-Woman aged 60 with Acromegaly starting at puberty, and hirsutism at the age of 30 . Note large adenomatous goitre. See text.

months, height $5 \mathrm{ft}$. (average $4 \mathrm{ft}$. 6 in.), weight I $28 \mathrm{lb}$. (average $70 \mathrm{lb}$.); B.P. I28/74. Red lineae distensae on abdomen and buttocks. No pubic hair. Seen nine months later, $5 \mathrm{ft} .4$ in., $122 \mathrm{lb}$.; red lineae distensae pale pink and white.

M.W., following measles at three years of age began to become fat. First seen at ten years of age, height $4 \mathrm{ft} .9$ in. (average $4 \mathrm{ft} .4$ in.), weight I $50 \mathrm{lb}$. (average $64 \mathrm{lb}$.); no pubic hair, multiple red lineae distensae on breasts and hips. One year later $4 \mathrm{ft}$. I I in., I $55 \mathrm{lb}$. The red lineae are now quite white.

The syndrome in girls therefore may be defined as adiposity, excessive height in childhood but ultimate height not excessive because of early union of epiphyses, normal or early menstruation and secondary sexual characteristics, and red or purple lineae distensae which may become white or disappear. The syndrome may commence after measles or scarlet fever, suggesting a hypothalmic mechanism. In this connection purple lineae distensae have been noted following meningitis treated by streptomycin. There seems little doubt that this syndrome in girls is not unrelated to the syndrome in boys, and probably has the same pathology. The delayed puberty or relative infantalism in boys as distinct from girls is paradoxical but so is the feminism of an adrenal tumour in an adult male compared with virilism

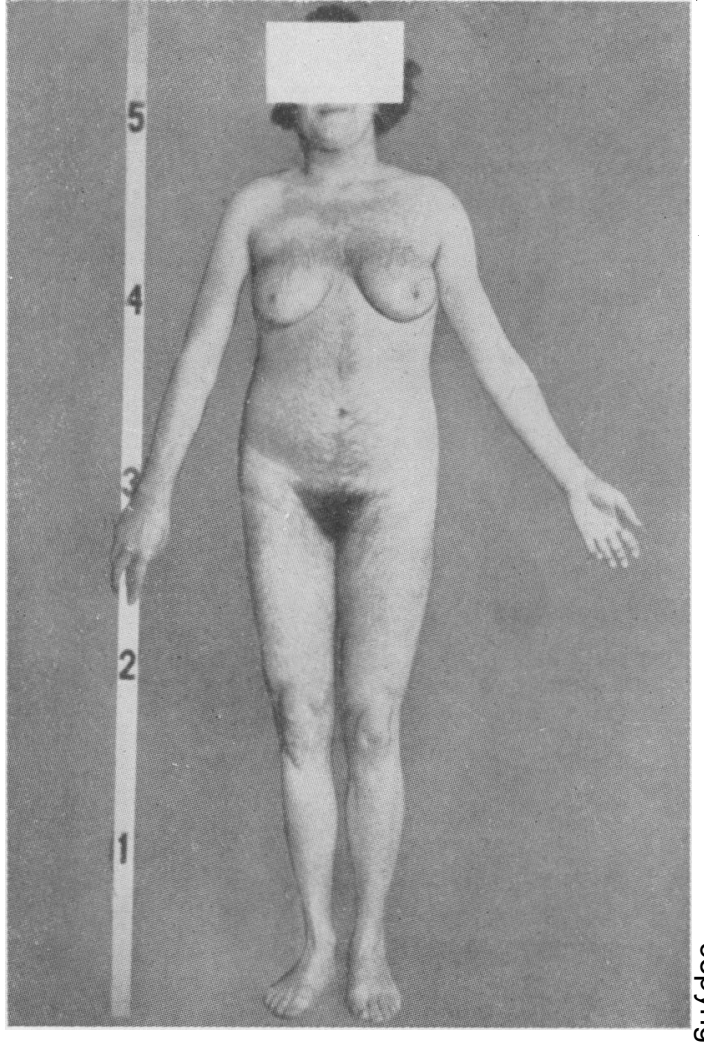

Fig. 6.-Virilism. Woman aged $2 \mathrm{I}$ at time of photograph. Menstruation was normal from age 14 to 16, when amenorrhoea developed, together with hirsutism, deepening of voice, and increase of weight. Radiography after uroselectan showed a right adrenal tumour, which was removed (age 2I), after which menstruation became regular once more but hirsutism persisted. The I 7-ketosteroids were very high (143 mg. per day) before operation and, although reduced by more than 50 per cent., still remain very high, namely $60 \mathrm{mg}$. per day as compared with the normal of 5 to $12 \mathrm{mg}$. This explains the persistent hirsutism 8 years after operation, and the probability of adrenal hyperplasia. or neoplasm in the remaining gland. A primary pituitary stimulas was postulated. Ten years later laparotomy did not reveal any neoplasm in the pelvis or adrenal areas. The left adrenal was moderately enlarged.

in a female. Of course, the term adipose gynandrism cannot be applied to these girls and for the moment nomenclature is left until further observation and thought has been given to their clinical observation, but there seems little doubt that we are approaching a clinical, if not a pathological basis for classification of adipose children and adolescence. As the feminine characteristics are normally present or accentuated in the female types, one might tentatively use the term adipose gynism in contrast to adipose gynandrism. 

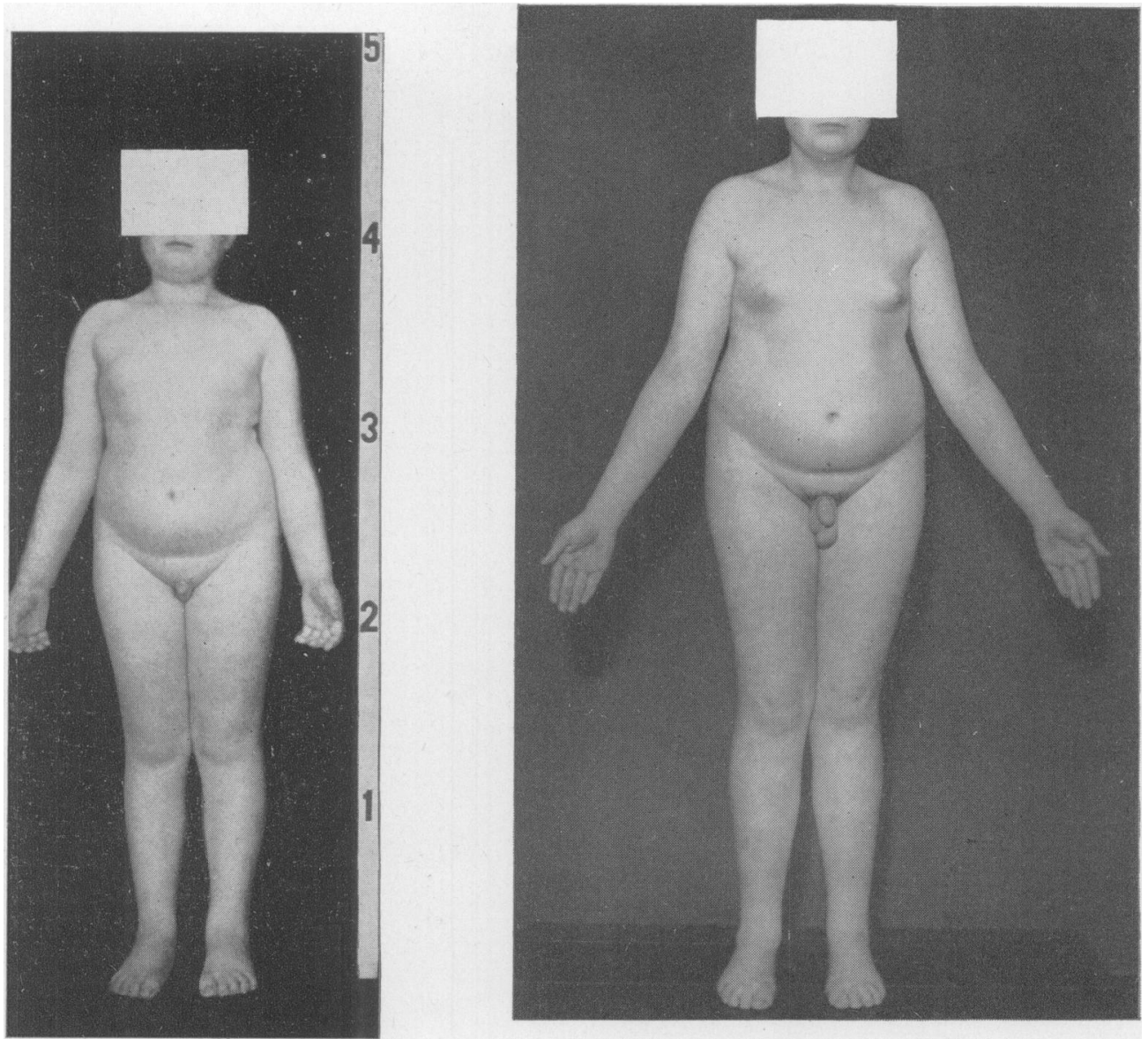

Fig. 7.-Adipose Gynandrism. Author's original case. Boy aged 8 and subsequently aged I 5. Delayed but spontaneous sexual maturity with persistence of feminine characteristics. Note wide pelvis and breasts.

The clinical and pathological situation is, however, still complex. Thus, for example, are lineae distensae an essential part of the syndromes, and must they be red or purple? If so, what is the diagnosis before they have appeared, after they turn white or disappear? Is excessive rate of growth at certain phases sufficient or essential for the diagnosis and is an advanced (radiologically determined) bone age an essential feature ? Further study must answer these questions but, as with other endocrine syndromes, there is no sharp dividing line between the full syndrome and the various intermediate and less complete forms.

The girls or adolescent women in this series did not suffer from hirsutism at the time of examination, but this factor may arise in cases not very dissimilar. Thus a girl of six years was seen because of adiposity. Her height was $4 \mathrm{ft}$. $\mathrm{I}$ in. (average $3 \mathrm{ft} .8$ in.) and her weight $6 \mathrm{r}$ lb. (average 45 lb.). She was fat in the face, chest, abdomen and breasts, and was somewhat plethoric. She had long dark hair (more than $\mathbf{I} \frac{1}{2}$ in. in length) on forearms, legs and back of neck, but no pubic hair. The mother stated that hair was present ' all over the body' from one year of age. No lineae distensae were present. The mother is o tall (5 ft. 6 in.) and plump, and says she was of $N$ similar build to the child as a girl, but never had 0 (and has not) any hair on the trunk or limbs. All her men folk are tall but her husband was average.

Since red lineae distensae are a feature of Cushing's syndrome, the question arises whether the group of cases described above can be said to represent Cushing's syndrome in childhood. They have not shown diabetic carbohydrate tolerance curves or osteoporosis of bones, but plethora, 


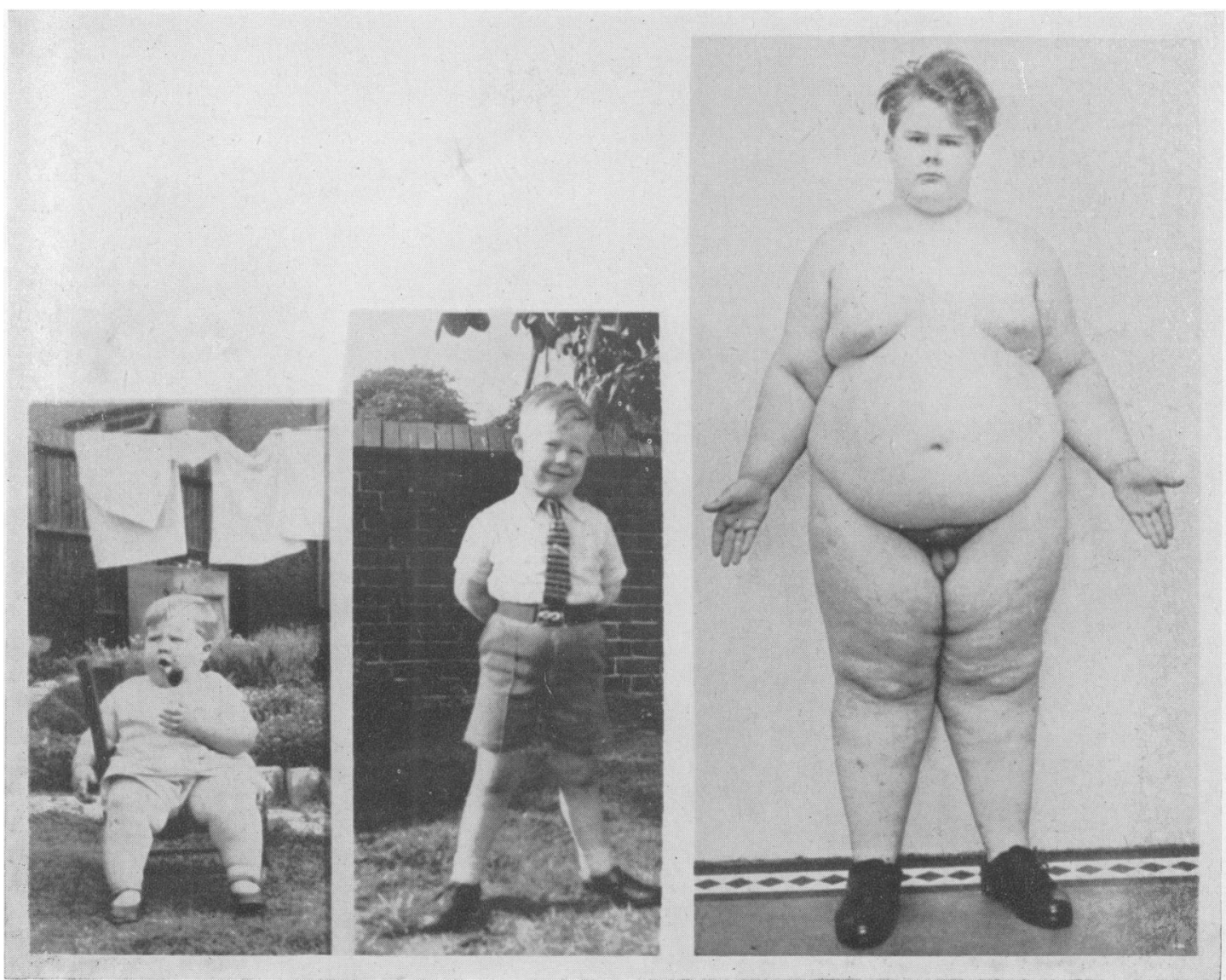

Fig. 8.-Adipose Gynandrism at the age of 3, 8 and $\mathrm{r} 6$ years. Weight 32 stone; scanty pubic and axillary hair; genitals of average size but voice high-pitched; red lineae distensae; wide pelvis and breasts. (See text.)

polycythaemia and (or) hypertension have occasionally been present. They do not have subcutaneous haemorrhages or gross cutis marmorata of the anterior tibial skin region, but as with many fat children they may have a bluish red mottling of the outer upper arm and buttocks, and this may also be present on the thighs and lower legs, sometimes with marble pattern appearance. Recently it has been noted that adrenocorticotropic hormone, or cortisone, produces pink abdominal lineae distensae (McNee, I950) and increases weight when used in patients with rheumatoid arthritis; and $\mathrm{Li}$ (1950) has found experimentally that pure adrenocorticotropic hormone results in fat deposition in tissues and liver, at the expense of protein, but is antagonistic to the growth hormone. A brief comparative review of Cushing's syndrome in childhood may not be irrelevant, since a probable explanation of the above syndrome is a pituitary-adrenal overactivity involving hypersecretion of adrenal oestrogens, I I-oxysteroids and other hormones.
Cushing's Syndrome in Childhood in Relation to Growth

Of Cushing's twelve original cases of young adults he observes that the female patients all appear to have been definitely undersized, the tallest being $5 \mathrm{ft} .3$ in. and the shortest $4 \mathrm{ft} .9$ in., whereas this was not true of the males and two were tall, $6 \mathrm{ft}$. $\mathrm{I} \frac{1}{2}$ in. and $6 \mathrm{ft}$. $\circ \frac{1}{2}$ in. However, the onset in these was mostly in adolescence. His case 5 was that of Oppenheimer and Fishberg (1924), a girl of 12 who at the age of five gained $75 \mathrm{lb}$. in a year; at the age of II she showed plethora, drowsiness, hair on the face, pubis and axillae, no menstruation, diabetes mellitus and hypertension $190 / 130$. She died at 12 and no height or bone radiology is given, but she was described as ' an undersized child.' Chute, Robinson and Donohue (1949), review Cushing's syndrome in childhood and describe a girl of eight who was normal until the age of four and then became fat and ceased to grow. She did not menstruate but pubic hair appeared at the age of 


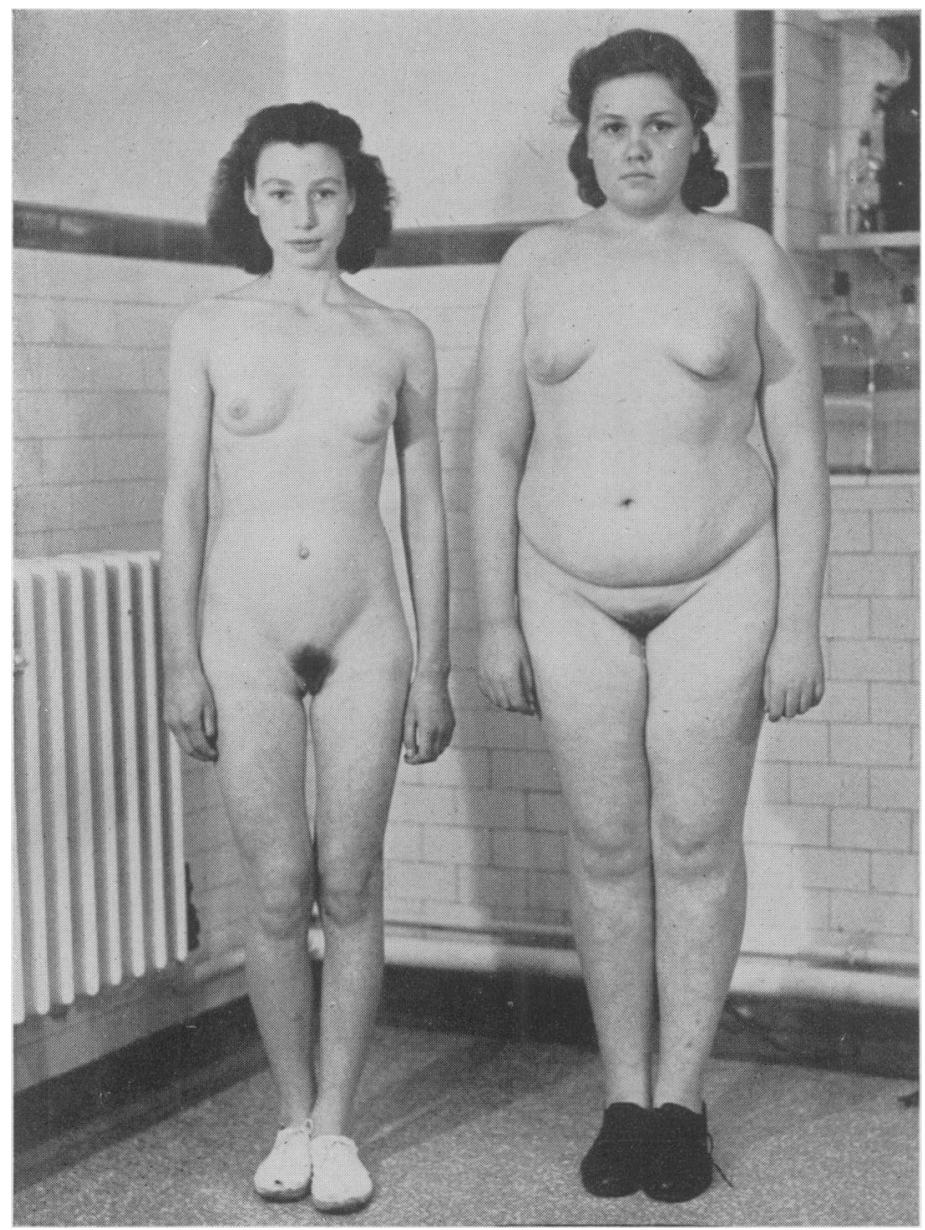

Fig. 9a.-Adipose Gynism. Girl aged 13, illustrating adipose gynism (see text). 은 Note height above normal; large areola of nipple; plethoric face, and $\vec{\nabla}$ (not well shown) purple lineae dis- 을.
tensae. Fig. 9b.-Same case. X-ray of knee-joint $\frac{0}{0} 0$
aged 13 years.

Fig. 9c.-Same case. Aged i4 years, showe. ing epiphyses almost closed.

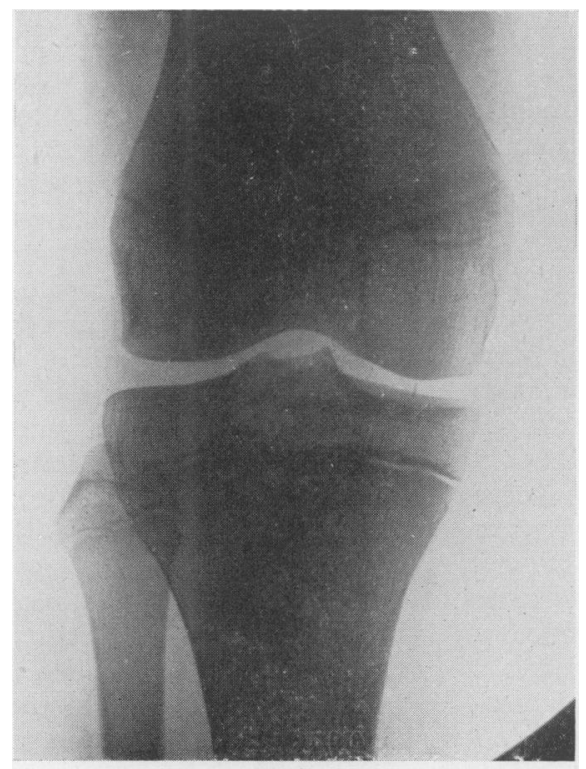

b.

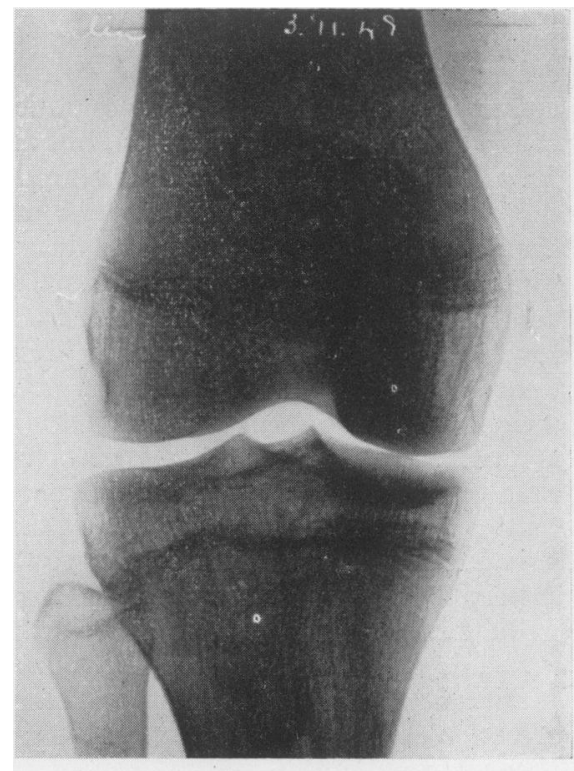

c. 
seven. Purple striae were present on abdomen and thigh, and the face was congested. B.P. 148/100. At the age of eight her height was $3 \mathrm{ft} .8 \mathrm{in}$. (average $4 \mathrm{ft}$.) and weight $65 \mathrm{lb}$. (average $53 \mathrm{lb}$.). Her ketosteroids were raised for a child (6.2 mg.), osteoporosis was present and there was a delayed fall in the carbohydrate tolerance curve. The adrenals were enlarged and contained nodular adenomata. Removal of one proved fatal. The pituitary showed Crooke's changes in the basophil cells. There was no note as to bone age or premature closure of epiphyses.

Walters, Wilder and Kepler (1934) describe a girl of nine who was normal until the age of four, when her mother noticed development of the breasts, general growth of hair all over her body and face and deepening of the voice. A year later she developed pubic hair and enlarged external genitals and clitoris. At eight she menstruated once. Her facial appearance was adult, her height $4 \mathrm{ft} .5$ in. (average $4 \mathrm{ft}$. 2 in.), and weight I03 lb. (average $58 \mathrm{lb}$.); obesity, purple striae on the abdomen, thighs and buttocks; B.P. 132/97. A large left adrenal adenocarcinoma was successfully removed with relief of symptoms. The authors considered the height within normal limits, but it is above average and the usually given normals include tall girls with endocrine tendencies. The bone age radiologically was 12 .

Crooke and Callow (1939) describe a girl of six with an adrenal tumour and Cushing's syndrome in which the height was average ( $3 \mathrm{ft} .8 \mathrm{in}$.), and another of 12 without adrenal tumour whose height was subnormal ( $4 \mathrm{ft}$., average $4 \mathrm{ft} .9$ in.).

It would 'therefore seem that Cushing's syndrome in girls is associated with average or subnormal height, only occasionally with height above average, and with normal or advanced bone age.

In males, Cushing's syndrome in childhood is rare, but is associated with an increased rate of growth. Forbes, Gustina and Postoloff (1943) describe 27 cases under 16 in the literature, 17 girls and Io boys. Of these boys, one aged I 5 with the full syndrome, was $5 \mathrm{ft}$. $8 \mathrm{in}$. in height (average $5 \mathrm{ft} .4$ in.), and was sexually mature with testes showing spermatogenesis. They consider that premature sexual maturity occurs in boys and girls with Cushing's syndrome. However, Josephson (1936) describes a case in a boy of 17 which commenced probably at the age of 10 when he became very fat, in which the genitals were infantile and the general appearance unvirile. Puberty had not occurred and an adrenal tumour was present.

These cases show some of the phenomena which have to be explained. Whether adipose gynandrism and gynism are really minor manifestations of
Cushing's syndrome in childhood can only be settled by further study.

With presenting sexual precocity in boys and girls, whatever the cause, e.g. third ventricle or hypothalamic tumours, adrenal tumour, interstitial cell tumour of the testis, granulosa cell tumours or hyperplasia of the ovaries, there is nearly always an increased growth rate, an advanced bone age and premature union of the epiphyses so that the abnormally tall child becomes an adult dwarf if the lesion is of a character which permits adult life to be reached. Biologically it would appear that excessive or premature secretion of androgens or oestrogens, whether their source be the gonads or adrenals or both, is responsible for the above growth and bone changes. Our therapeutic experience in dwarfism and infantilism suggests that androgens are much more potent than oestrogens in stimulating growth, but that the oestrogens may be more important than the androgens in determining epiphyseal closure. Both boys and girls may have a spurt of growth at the time of puberty, but in a proportion of girls growth ceases within a year or so of the first menstruation owing to closure of the epiphyses whereas in males this rarely occurs before the age of 17 .

Figs. 4 and 7 are reproduced from Dr. Leonard Simpson's book, 'Major Endocrine Disorders, by kind permission of the Oxford University Press.

\section{AdDENDUM}

Since writing this article $I$ have received a personal communication from Dr. R. G. Sprague which supplements my reference in the above article to McNee's American impressions.

Sprague's letter refers to experience at the Mayo Clinic to the effect that cortisone can produce, or in some cases intensify, red or purple lineae distensae, and that the effect varies with the intensity of treatment and the cessation of same. It appears to me that these observations are of considerable importance, far beyond the sphere of endocrine therapy in which they have been recorded. They would indicate that in any patient in which coloured lineae distensae appeared, or were present, it can be concluded with a reasonable measure of confidence that the adrenal glands are secreting an excess of cortisone, and that their hyperfunction is therefore playing an important part in the pathology of the condition observed. It is my view that this will permit the diagnosis of hypercorticalism, primary or secondary to hyperpituitarism, in a number of conditions as well as the classical syndrome to which the name of Cushing's syndrome has been applied. 


\title{
BIBLIOGRAPHY
}

ALBRIGHT, F., SMITH, P. H., and FRASER, R. (1942), צ. Clin.

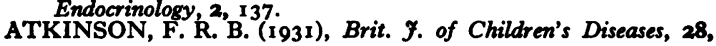
I2I.

BAUER, W., and AUB, J. C. (194I), 7. Clin. Invest., 20, 295.

CHUTE, A. L., ROBINSON, G. C., and DONÖHUE,' W. L.

COGGES), Y. Paediatrics, 34, I. 26, 1 .

CROOKE, A. C., and CALLOW, R. K. (1939), Quart. F. Med.,

CUSHING, H. (1912), 'The Pituitary Body and its Disorders,' J. B. Lippincott \& Co., Philadelphia.

CUSHING, H., and DAVIDOFF, L. M. (1927), ' Rockefeller Institute for Medical Research Monographs,' New York.

DAVIDOFF, L. M. (1926), Endocrinology, 10, 461.

DAVIS, A. C. (1940), "Transactions of Amer. Assoc. for Study of Goitre.

ELLINGER, P., HARE, D. C., and SIMPSON, S. L. (1937), Quart. F. Med., 6, 24I.

ELLIIS, F. (1949), Proc. Roy. Soc. Med., 42, 853.

FORBES, J. E., GUSTINA, F. G., and POSTOLOFF, A. V. (1943), Amer. F. Dis. Child., 45, 593.
GOLDBERG, M. B., and LISSER, H. (1942), צ. Clin. EndoHURXTHAgl, 2, 477. M., HARE, H. F. E., HORRASE, G., and POPPEN, J. L. (1949), Ұ. Clin. Endocrinology, 9, 126. JOSEPHSON, B. (1936), Acta. Med. Scand., $90,385$.

KINSELL, L. W., MICHAELS, G. D., LI, C. H., and LARSEN, W. E. (1948), 7 . Clin. Endocrinology, 8, 1013.

LI C. H. (1950), Lancet, $1,213$.

MÁINZER, F., and YẢLAỨSis, E. (1937), Folia Clin. Orient., I, 37.

MCNEE, J. W. (1950), Brit. Med. F., I, 113.

NORTHFIELD D. W. C. (I949), Proc. Roy. Soc. Med., 42, 845 OPPENHEIMER, B. S., and FISHBERG, A. M. (1924), Arch. Int. Med., 34, 631 .

SCHRIRE, J., and SHARPEY-SCHAFER, E. P. (1938), Clinical

Science, 3, 413.
SCHRIRE, J. (1948), F. Endocrinology (Gt. Britain), 5, 274 .

SIMPSON, S. L. (I048), 'Major Endocrine Disorders,' Oxford University Press, London.

TURNER, H. H. (I938), Endocrinology, 23, 566.

WALTERS, W., WILDER, M., and KEPLER, E. J. (1934), Annals of Surgery Oct. p. 670 .

YOUNG, F. G. (1937), Lancet, 2, 372.

\section{DIABETES INSIPIDUS}

\author{
By A. A. G. Lewis, B.Sc., M.D., M.R.C.P. \\ Saltwell Research Fellow, the Royal College of Physicians \\ From the Medical Professorial Unit, The Middlesex Hospital
}

Thomas Willis, in 1682 , distinguished between saccharine and non-saccharine diabetes. Frank (in 1794) defined diabetes insipidus as a long-continued, abnormally-increased secretion of non-saccharine urine, not caused by renal disease. It is now known to be due to a failure of water reabsorption by the renal tubules as the result of an ineffective level of circulating anti-diuretic hormone (ADH). Cases where the renal tubules can be shown to be insensitive to the action of the hormone occur extremely rarely (Williams, 1946).

\section{Clinical Picture}

Diabetes insipidus may occur at any age, but is more common in the young. In Jones' series of 42 cases (1944), 17 occurred in the first ten years of life. Males are more often affected than females.

The onset is usually insidious, the patient noticing a tendency to thirst and dryness of the mouth, with polyuria and nocturia. There may be some loss of appetite, and the dryness of the mouth may make mastication difficult and food less appetizing. Loss of weight may occur, though some cases gain. Loss of appetite and exhaustion from loss of sleep may lead to emaciation in severe cases. Occasionally the appetite is increased.

In a few cases the onset is sudden and dramatic with intense, unquenchable thirst and polyuria. These patients may remember for years exactly when and where their illness began and may say that the thirst occurred after some particular food had been eaten. Sometimes a shock or an accident may be blamed.

In severe cases the thirst is extreme, the patient developing a dry mouth if he abstains from fluid for more than an hour or so. Very often the thirst seems to be abnormal in quality as well. It may be described in dramatic terms, the patient emphasizing the 'burning sensation' in the mouth and throat. Sipping water is only a temporary palliative however; the patient often feels compelled to drink a large quantity of waterhe feels he must 'drain the glass to the dregs' or ' get it right down inside.' Water is often preferred to all other fluids and some patients become connoisseurs of water, preferring that from one source to that from another in flavour. Many find iced water more satisfying.

Deprived of water, the sufferer may go to any lengths to get fluid, drinking from flower vases, puddles or fountains, or filling his mouth with snow, or even drinking his own urine. It is not surprising that some of these patients, constantly tortured by thirst, unable to follow any normal occupation on account of the polyuria and prevented from sleeping for more than an hour or so at a time, should develop neurotic symptoms. Headaches, apathy, weakness, inability to concentrate, irritability and insomnia may be com- 